\title{
Characterization of rubber particles and rubber chain elongation in Taraxacum koksaghyz
}

\author{
Thomas Schmidt ${ }^{1 \dagger}$, Malte Lenders ${ }^{1 \dagger}$, Andrea Hillebrand ${ }^{1}$, Nicole van Deenen ${ }^{1}$, Oliver Munt ${ }^{1}$, Rudolf Reichelt ${ }^{2}$, \\ Wolfgang Eisenreich ${ }^{3}$, Rainer Fischer ${ }^{4}$, Dirk Prüfer ${ }^{1,4}$, Christian Schulze Gronover $^{4^{*}}$
}

\begin{abstract}
Background: Natural rubber is a biopolymer with exceptional qualities that cannot be completely replaced using synthetic alternatives. Although several key enzymes in the rubber biosynthetic pathway have been isolated, mainly from plants such as Hevea brasiliensis, Ficus spec. and the desert shrub Parthenium argentatum, there have been no in planta functional studies, e.g. by RNA interference, due to the absence of efficient and reproducible protocols for genetic engineering. In contrast, the Russian dandelion Taraxacum koksaghyz, which has long been considered as a potential alternative source of low-cost natural rubber, has a rapid life cycle and can be genetically transformed using a simple and reliable procedure. However, there is very little molecular data available for either the rubber polymer itself or its biosynthesis in T. koksaghyz.

Results: We established a method for the purification of rubber particles - the active sites of rubber biosynthesis from T. koksaghyz latex. Photon correlation spectroscopy and transmission electron microscopy revealed an average particle size of $320 \mathrm{~nm}$, and ${ }^{13} \mathrm{C}$ nuclear magnetic resonance (NMR) spectroscopy confirmed that isolated rubber particles contain poly(cis-1,4-isoprene) with a purity $>95 \%$. Size exclusion chromatography indicated that the weight average molecular mass ( $\overline{\mathrm{M}}$ w) of $T$. koksaghyz natural rubber is 4,000-5,000 kDa. Rubber particles showed

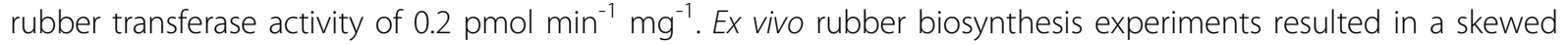
unimodal distribution of $\left[1-{ }^{14} \mathrm{C}\right]$ isopentenyl pyrophosphate (IPP) incorporation at a $\overline{\mathrm{M}} \mathrm{w}$ of 2,500 kDa.

Characterization of recently isolated cis-prenyltransferases (CPTs) from T. koksaghyz revealed that these enzymes are associated with rubber particles and are able to produce long-chain polyprenols in yeast.

Conclusions: T. koksaghyz rubber particles are similar to those described for $\mathrm{H}$. brasiliensis. They contain very pure, high molecular mass poly(cis-1,4-isoprene) and the chain elongation process can be studied ex vivo. Because of their localization on rubber particles and their activity in yeast, we propose that the recently described T. koksaghyz CPTs are the major rubber chain elongating enzymes in this species. T. koksaghyz is amenable to genetic analysis and modification, and therefore could be used as a model species for the investigation and comparison of rubber biosynthesis.
\end{abstract}

\section{Background}

Natural rubber poly(cis-1,4-isoprene) with a molecular mass of $10-10,000 \mathrm{kDa}$ is one of the most important industrial raw materials in the world, and its sole commercial source is currently the para rubber tree Hevea brasiliensis [1]. Other sources, such as Russian dandelion (Taraxacum koksaghyz Rodin) and Guayule (Parthenium argentatum), could be useful in the event of

\footnotetext{
* Correspondence: c.sg@uni-muenster.de

+ Contributed equally

${ }^{4}$ Fraunhofer Institut für Molekularbiologie und Angewandte Ökologie, Forckenbeckstr. 6, 52074 Aachen, Germany
}

supply shortages as well as providing a suitable alternative for people with allergies to hevein, a major allergen present in $H$. brasiliensis latex [2,3].

The biosynthesis of natural rubber takes place in the latex of laticifers or specialized parenchyma cells in the bark [1], where it is stored in rubber particles as an end product. Ultrastructural analysis of rubber particles from different species [4-6] revealed an almost identical globular structure that contains a homogeneous hydrophobic rubber core surrounded by an intact monolayer membrane. The monolayer membrane includes a mixture of lipids, proteins and other molecules with the hydrophilic 
portions of the phospholipids and glycosylated particlebound proteins facing the cytoplasm [6-10]. The size of rubber particles ranges from $0.08-2 \mu \mathrm{m}$ in $H$. brasiliensis, 0.2-6.5 $\mu \mathrm{m}$ in Ficus species and 1-2 $\mu \mathrm{m}$ in P. argentatum $[6,11]$.

Natural rubber is synthesized by adding activated 2methyl-1,3-butadiene (isopentenyl diphosphate, IPP) to the growing chain $[12,13]$. This reaction is catalyzed by specific long-chain cis-prenyltransferases (CPTs, EC 2.5.1.20), which are probably located on the surface of rubber particles. According to their function, CPTs are classified as short-, medium- or long-chain polymerizing enzymes and can be distinguished from trans-prenyltransferases (TPTs) by the presence of five conserved protein motifs [14]. They are found in bacteria [15], yeast [16], animals including humans [17] and plants [18-22].

Recently, two CPTs (RER2 and SRT1) were isolated from Saccharomyces cerevisiae and were shown to be responsible for the biosynthesis of dolichol, a long-chain polyprenol with a saturated alpha-isoprene unit, which serves as a glycosyl carrier for protein glycosylation in the endoplasmic reticulum [23]. The first plant CPT was identified in Arabidopsis thaliana (ACPT), and appears to be required for normal growth and development [24]. The latex of $H$. brasiliensis contains at least two CPTs, designated HRT1 and HRT2 (for Hevea rubber transferase). The addition of recombinant HRT2 to washed latex particles supplemented with radioactively-labeled IPP resulted in the significant production of a highmolecular-weight labeled rubber product, whereas recombinant HRT1 showed no significant activity [25]. In vitro, initiation of rubber biosynthesis by HRT requires intact particles, isopentenyl diphosphate (IPP), allylic diphosphates such as farnesyl diphosphate (FPP) and divalent metal cations $\left(\mathrm{Mg}^{2+}\right.$ or $\left.\mathrm{Mn}^{2+}\right)$ as a co-factor [26-28]. However, all attempts to purify a functional rubber transferase from rubber particles have failed, suggesting that the native enzyme needs additional factors for its activity [29].

In this study, we report the comprehensive analysis of rubber particles from T. koksaghyz. The rubber particles contained very pure poly(cis-1,4-isoprene) and retained their capacity to produce natural rubber ex vivo. Immunological analysis revealed that CPTs associated with these particles remain fully functional when expressed as recombinant proteins either in Saccharomyces cerevisiae or tobacco protoplasts.

\section{Results and Discussion}

\section{Physical characterization of purified T. koksaghyz} rubber particles

Rubber particles examined by transmission electron microscopy at low magnification appeared approximately spherical, with diameters ranging from 0.2 to almost $1 \mu \mathrm{m}$ (Figure 1a). At higher magnification, additional small and mostly spherical particles became visible with the smallest barely $10 \mathrm{~nm}$ in diameter (Figure 1b). Frequently, those rubber particles touching each other were deformed by the effect of surface tension in the staining solution during air-drying [30]. A similar unimodal particle size distribution ranging from 0.2-0.7 $\mu \mathrm{m}$ was observed by photon correlation spectroscopy, using rubber particles from the latex of 4-month-old and 1-year-old T. koksaghyz plants (Figure 1c). The average size of the rubber particles was $320 \mathrm{~nm}$, and more than $50 \%$ of particles were in the size range 250 $400 \mathrm{~nm}$. The age of the plants appeared not to affect particle size. Size exclusion chromatography (SEC) analysis of both samples revealed an weight average molecular mass of $\sim 4,750 \mathrm{kDa}$ with a unimodal distribution, which again showed no significant variation as a function of plant age (data not shown).

\section{Concentration and chemical properties of T. koksaghyz rubber}

The concentration of rubber in the latex of greenhousecultivated T. koksaghyz plants was monitored from 4-18 months after sowing, revealing an increase during the first 8 months after which the concentration leveled off and remained constant at 130-150 mg dry rubber $\mathrm{ml}^{-1}$ latex thereafter. Although the absolute rubber concentration varies in different T. koksaghyz accessions and under different growth conditions, our results agree with earlier investigations of rubber production in fieldgrown T. koksaghyz plants, where rubber accumulated only during the first growth season and then remained at constant levels [31]. To determine the chemical properties of T. koksaghyz rubber, we performed one- and two-dimensional NMR analysis of isolated rubber particles dissolved in dichloromethane. The ${ }^{13} \mathrm{C}$ NMR spectrum displayed five dominant signals at chemical shifts indicative for poly(cis-1,4-isoprene), but not for poly (trans-1,4-isoprene) (Table 1 and Figure 2) [32]. Notably, the ${ }^{13} \mathrm{C}$ NMR chemical shifts of C-4 and C-5 differ by more than $5 \mathrm{ppm}$ for the cis- and trans-configured compounds (Table 1). Therefore, the observed frequencies leave no doubt that T. koksaghyz rubber is poly(cis1,4-isoprene). Moreover, all ${ }^{1} \mathrm{H}^{13} \mathrm{C}$ and ${ }^{1} \mathrm{H}^{1} \mathrm{H}$ correlations detected in two-dimensional HMQC and COSY experiments, respectively, fully agreed with the couplings expected for poly(cis-1,4-isoprene) (Table 1). The NMR spectra contained few low-intensity signals arising from impurities, indicating that the purity of poly(cis-1,4-isoprene) in T. koksaghyz rubber is $>95 \%$.

\section{In vitro biosynthetic activity of rubber particles}

The rubber biosynthetic activity of T. koksaghyz rubber particles was characterized in vitro by assaying the 

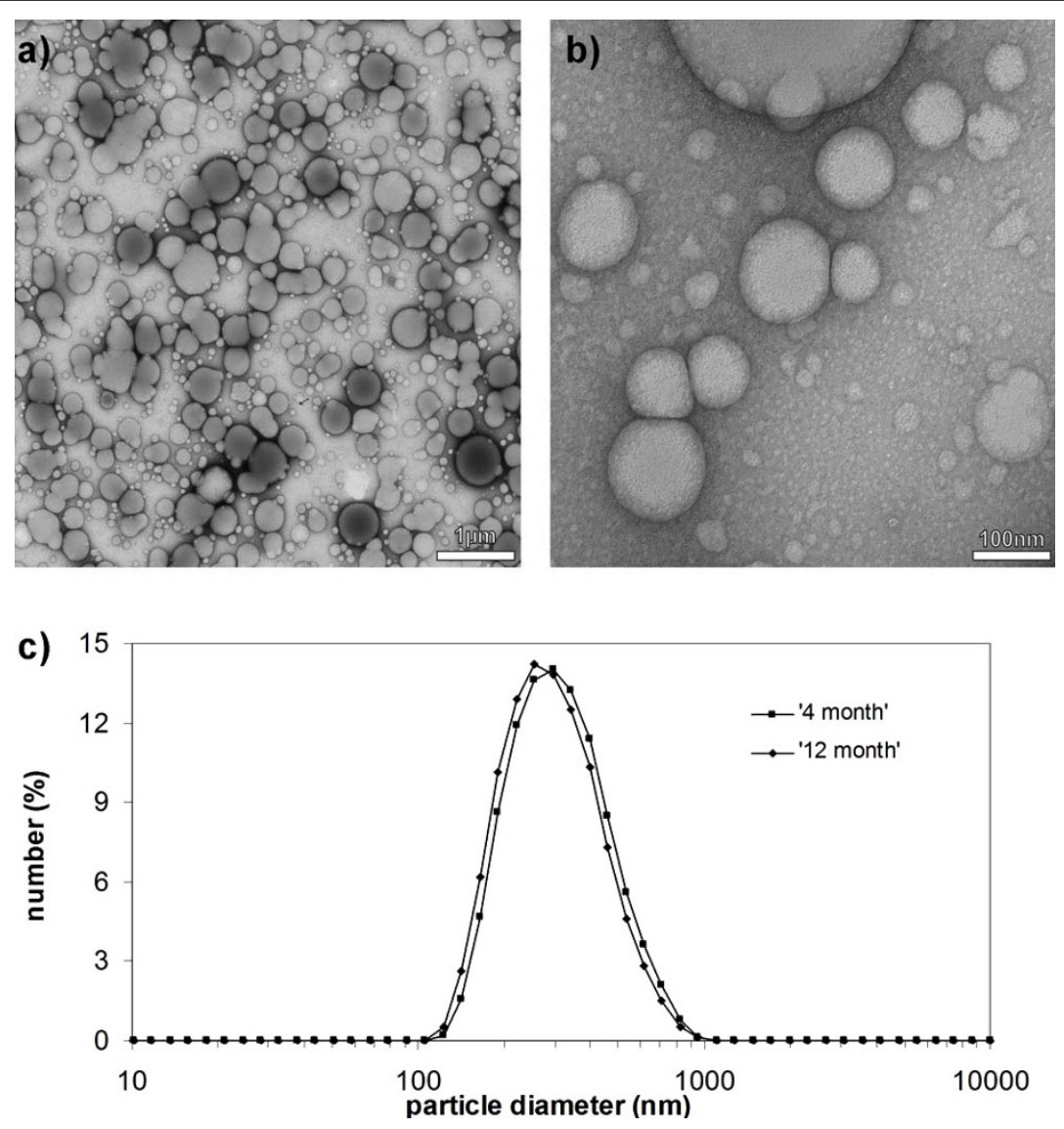

Figure 1 Morphology of rubber particles from Taraxacum koksaghyz. Transmission electron micrographs at low a) and high b) magnification. c) Rubber particle size distribution measured by photon correlation spectroscopy in latex of 4-and 12-month-old plants. Magnifications in a) and b) are indicated by bar size.

Table 1 NMR data of poly(cis-1,4-isoprene) from T. koksaghyz.

\begin{tabular}{ccccccc}
\hline & \multicolumn{2}{c}{ Chemical shifts* } & \multicolumn{2}{c}{ Observed correlations in } & \multicolumn{2}{c}{ Published ${ }^{\mathbf{1 3}}$ C-NMR chemical shifts** } \\
Position & ${ }^{{ }^{*} \mathbf{H}[\mathrm{ppm}]}$ & ${ }^{\mathbf{1 3}^{*} \mathbf{C} \text { [ppm] }}$ & COSY & HMBC & cis-Polyisoprene & trans-Polyisoprene \\
\hline 1 & 2.1 & 27.0 & 2 & 4 & 26.3 & 26.4 \\
2 & 5.2 & 124.0 & $1,5(\mathrm{w})^{* * *}$ & $5,1,4$ & 124.8 & 123.9 \\
3 & & 134.2 & & 1,5 & 134.8 & 134.5 \\
4 & 2.1 & 31.4 & & 5,1 & 31.8 & 39.3 \\
5 & 1.7 & 22.3 & $1(\mathrm{w})$ & 4 & 22.9 & 15.3 \\
\hline
\end{tabular}

* referenced to the solvent signals; ${ }^{*}[32] ;{ }^{* * *}(w)$, weak cross peak

The solvent was $\mathrm{CD}_{2} \mathrm{Cl}_{2}$.

incorporation of the radiolabeled precursor IPP, which should become incorporated into the polymer and thus trapped in the rubber particles $[21,33]$. The IPP incorporation assay was carried out using intact isolated rubber particles as well as particles pre-treated with proteinase $\mathrm{K}$ to destroy particle-associated enzymes and other proteins. The treated and untreated particles were tested by SDSPAGE and Coomassie Brilliant Blue staining, showing that the protein bands normally found in the particles were eliminated by proteinase $\mathrm{K}$ treatment (data not shown).
This control allowed us to distinguish between physical and enzymatic incorporation of IPP into the particle, but had no influence either on particle integrity or stability. Earlier investigations into the in vitro activity of rubber particles used boiled particles as a control [33], which was not suitable for T. koksaghyz particles because of their rapid temperature-dependent agglomeration which changes the surface area to which IPP could be attached.

In time course experiments, T. koksaghyz rubber particles enzymatically incorporated increasing amounts of 


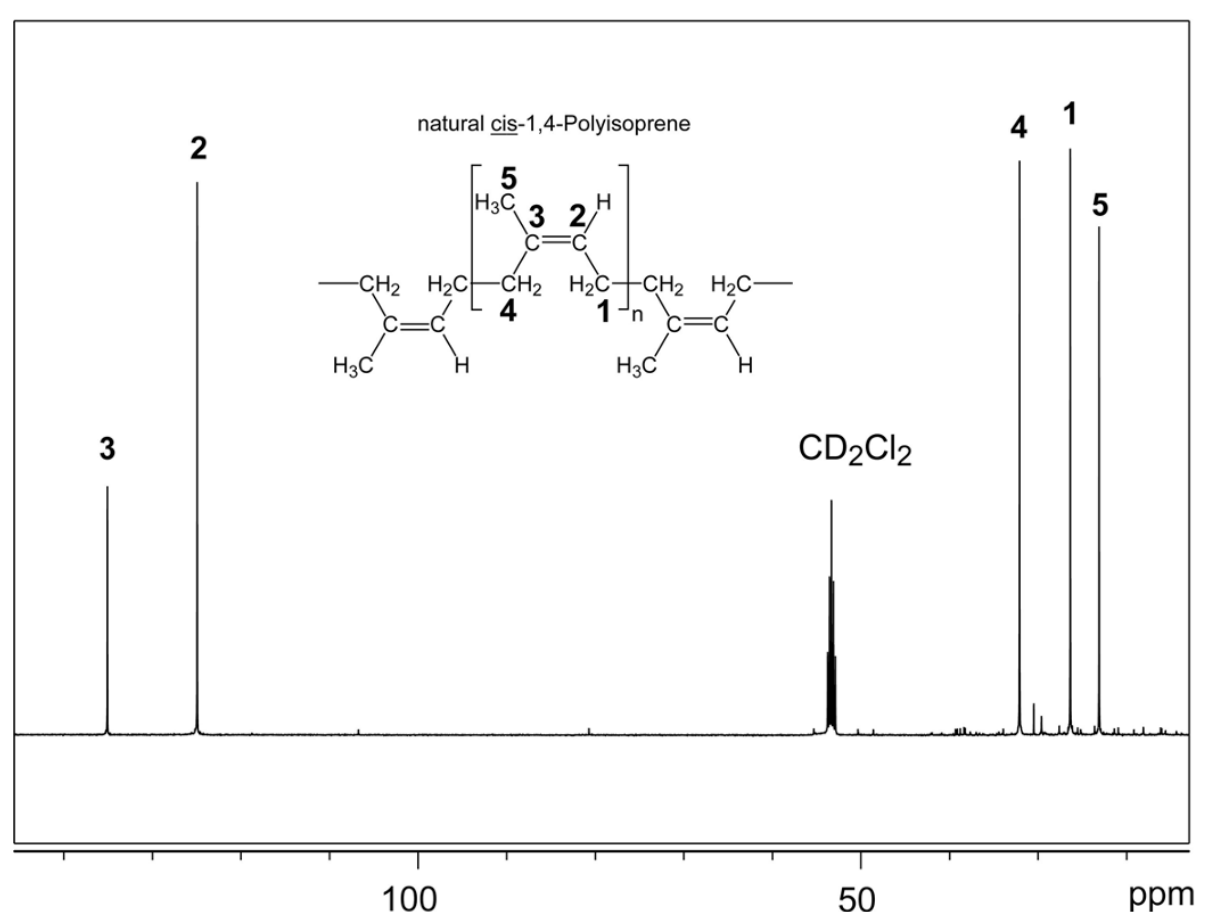

Figure $2{ }^{13} \mathrm{C}$ NMR spectrum of rubber particles isolated from Taraxacum koksaghyz. The signal arising from the deuterated sample is indicated. The inset displays the structure and the carbon numbering for poly(cis-1,4-isoprene).

$\left[1-{ }^{14} \mathrm{C}\right] \mathrm{IPP}$ over the incubation time (Figure 3a). Saturation was achieved after $2 \mathrm{~h}$, possibly reflecting the loss of chain elongation activity due to the particles becoming unstable as reported for other rubber-producing plants [29]. The incorporation of $\left[1-{ }^{14} \mathrm{C}\right] \mathrm{IPP}$ also increased as more rubber particles were added to the reaction, giving a sigmoid curve progression that reflected an enzymatic incorporation process. The enzymatic activity of T. koksaghyz rubber particles in vitro was about $0.2 \mathrm{pmol} \mathrm{min}{ }^{-1} \mathrm{mg}^{-1}$.

To calculate the rubber transferase activity of the rubber particles, IPP incorporation was measured as a function of protein concentration (Figure $3 \mathrm{~b}$ ), whereas the mean amount of protein in T. koksaghyz rubber particles remained approximately constant at $70-80 \mu \mathrm{g} \mathrm{mg}^{-1}$. This allowed us to calculate the enzymatic $\left[1-{ }^{14} \mathrm{C}\right] \mathrm{IPP}$ incorporation activity of $2.6-3 \mathrm{pmol} \mathrm{min}^{-1} \mathrm{mg}^{-1}$ rubber particle protein, which corresponds to the findings for rubber particles from other plants $\left(0.08-13 \mathrm{pmol} \mathrm{min}^{-1}\right.$

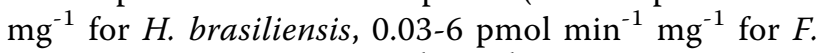
carica and $1.3 \mathrm{pmol} \mathrm{min}^{-1} \mathrm{mg}^{-1}$ for $P$. argentatum $[27,33,34])$. The range of rubber particle activity observed within each species could reflect the different assay conditions and particle extraction methods. For example, rubber transferase activity is thought to be $\mathrm{Mg}^{2+}$-dependent [35], and the concentration of $\mathrm{Mg}^{2+}$ may differ between species, whereas optimal concentrations for $H$. brasiliensis and $P$. argentatum were $2 \mathrm{mM}$ and $8 \mathrm{mM}$, respectively $[33,36]$. We therefore varied the $\mathrm{Mg}^{2+}$ concentrations in the in vitro rubber transferase assay for T. koksaghyz rubber particles, and found the optimal activity at 4-5 $\mathrm{mM} \mathrm{Mg}^{2+}$ (Table 2). To verify that rubber chain elongation in T. koksaghyz rubber particles occurred by the transfer of IPP in the cis-configuration, a sophisticated labeling assay was developed in which rubber particles were incubated with $[1,2,4$ ${ }^{13} \mathrm{C}_{3}$ ] IPP, vacuum dried and the residual material dissolved in $\mathrm{CD}_{2} \mathrm{Cl}_{2}$ for ${ }^{13} \mathrm{C}$ NMR analysis. The ${ }^{13} \mathrm{C}$ NMR signal of $\mathrm{C}-2$ poly(cis-1,4-isoprene) (Figure 3c) showed, in addition to the intense central signal, pairs of coupling satellites characterized by coupling constants of 73 $\mathrm{Hz}$ (coupling to ${ }^{13} \mathrm{C}-3$ ) and $44 \mathrm{~Hz}$ (coupling to ${ }^{13} \mathrm{C}-1$ ). The $\mathrm{C}-1$ satellite pair was approximately three times more intense than the $\mathrm{C}-3$ pair (Figure 3c), indicating that isotopologues with adjacent ${ }^{13} \mathrm{C}-1$ and ${ }^{13} \mathrm{C}-2$ were slightly enriched in accordance with their biosynthetic origin from $\left[1,2,4-{ }^{13} \mathrm{C}_{3}\right]$ IPP (cf. filled circles in Figure $3 c$ ). The low enrichment factor can be explained by the large excess of unlabeled poly(cis-1,4-isoprene) at the beginning of the labeling reaction. Nevertheless, the non-stochastic distribution of the satellite pairs provides additional evidence for cis-prenyltransferase activity under these experimental conditions.

The distribution of $\left[1-{ }^{14} \mathrm{C}\right] \mathrm{IPP}$ transfer to existing rubber molecules of different molecular masses was investigated by SEC (Figure 4 and Table 3). This revealed a 
a)

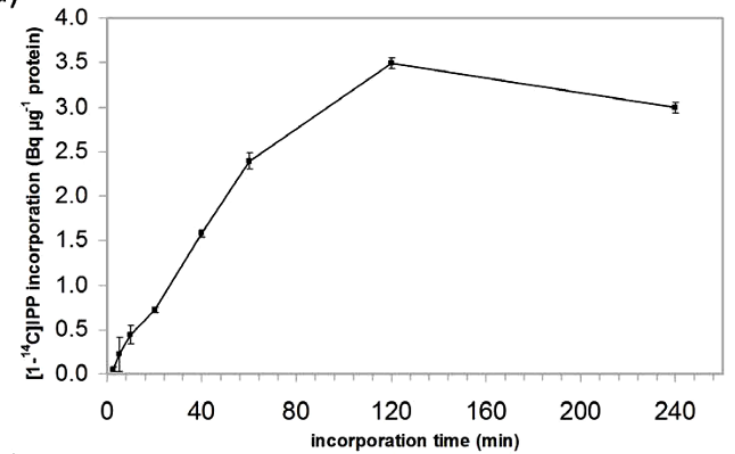

b)

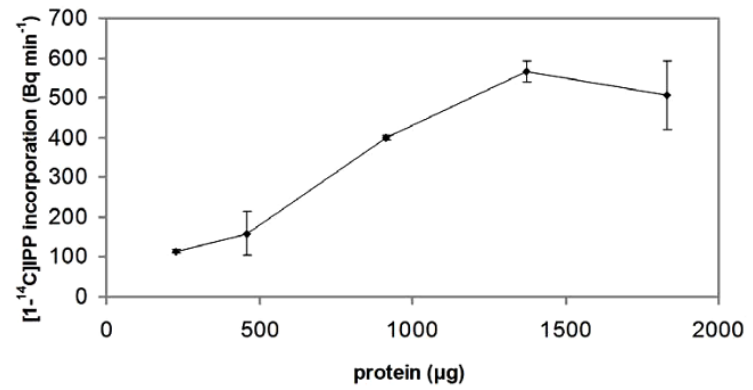

c)

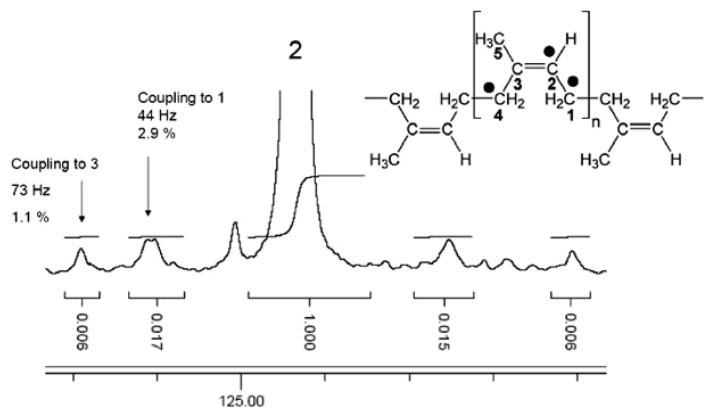

Figure 3 Incorporation of IPP into rubber particles. a) Time course-dependent and b) rubber particle protein dependent incorporation of [1$\left.{ }^{14} \mathrm{C}\right] \mathrm{IPP}$. c) ${ }^{13} \mathrm{C}$ NMR signal of $\mathrm{C}-2$ of poly(cis-1,4-isoprene) from the labeling experiment with $\left[1,2,4-{ }^{13} \mathrm{C}_{3}\right] \mathrm{IPP}$. The filled circles indicate ${ }^{13} \mathrm{C}$ atoms from $\left[1,2,4-{ }^{13} C_{3}\right]$ IPP. Values in a) and b) represent mean ( \pm standard deviation) from three biological repetitions.

Table 2 Effect of $\mathrm{Mg}^{2+}$ ion on $\left[1-{ }^{14} \mathrm{C}\right] \mathrm{IPP}$ incorporation of T. koksaghyz rubber particles.

\begin{tabular}{cc}
\hline $\mathbf{M g C l}_{2}[\mathrm{mM}]$ & $\begin{array}{c}{\left[\mathbf{1}^{\mathbf{1 4}} \mathbf{C}\right] \mathrm{IPP} \text { incorporation }} \\
{\left[\mathbf{B q} \mathbf{~ g g}^{-1} \text { protein] }\right.}\end{array}$ \\
\hline $2 \mathrm{mM}$ & $0.57( \pm 0.023)$ \\
$3 \mathrm{mM}$ & $0.83( \pm 0.037)$ \\
$4 \mathrm{mM}$ & $0.89( \pm 0.039)$ \\
$5 \mathrm{mM}$ & $0.91( \pm 0.040)$ \\
$7.5 \mathrm{mM}$ & $0.52( \pm 0.023)$ \\
$10 \mathrm{mM}$ & $0.04( \pm 0.002)$ \\
\hline
\end{tabular}

For the ex vivo rubber biosynthesis experiment $3 \mathrm{mg}$ of freshly prepared rubber particles was incubated for $60 \mathrm{~min}$ with $\left[1-{ }^{14} \mathrm{C}\right] \mathrm{PP}$ in IPP assay buffer containing different concentrations of $\mathrm{Mg}^{2+}$ ion. Values represent mean $( \pm$ standard deviation) from three biological repetitions. typical skewed unimodal mass, with a weight average molecular mass $(\overline{\mathrm{M}} \mathrm{w})$ of $5,170 \mathrm{kDa}( \pm 134 \mathrm{kDa})$ and number average molecular mass $(\overline{\mathrm{M}} \mathrm{n})$ of $2,460 \mathrm{kDa}$ $( \pm 142 \mathrm{kDa}$ ), indicating a low level polydispersity of 2.1 . Again, the incorporation of $\left[1-{ }^{14} \mathrm{C}\right] \mathrm{IPP}$ increased with the incubation time (Figure 4a). After $5 \mathrm{~min}$ the incorporation of $\left[1-{ }^{14} \mathrm{C}\right] \mathrm{IPP}$ occurred at a significantly higher rate in untreated particles compared to those treated with proteinase $K$, whereas the means of labeled material were $2,760 \mathrm{kDa}$ for $\overline{\mathrm{M}} \mathrm{w}$ and $672 \mathrm{kDa}$ for $\overline{\mathrm{M}} \mathrm{n}$, respectively. Furthermore, the SEC data indicated that in vitro rubber chain elongation occurred over a broad range (1-5000 $\mathrm{kDa})$, whereas the highest incorporation 


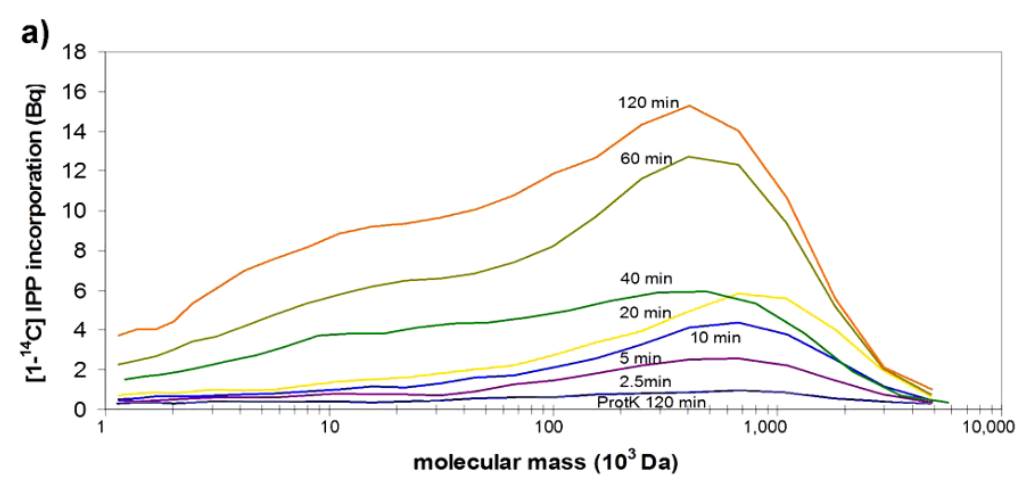

b)

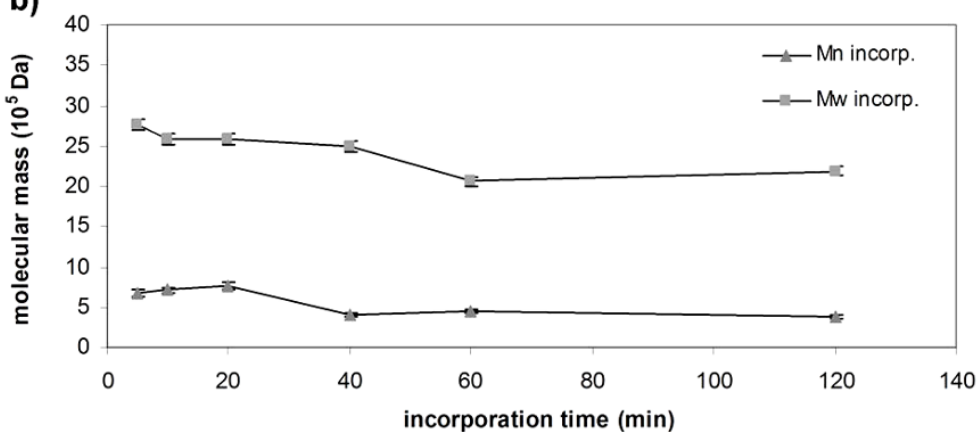

Figure 4 Molecular mass distribution of $\left[1-{ }^{14} \mathrm{C}\right] \mathrm{IPP}$-labeled rubber synthesized in vitro. a) SEC profile of labeled material. b) $\overline{\mathrm{M}}$ w and $\overline{\mathrm{M}} \mathrm{n}$ of the labeled polymer. IPP incorporation assay was performed and stopped after the time points shown. Extracted polymer material was fractionated by SEC and the radioactivity of the resulting fractions was determined by scintillation. Proteinase K (ProtK)-treated particles controlled for IPP trapped on the rubber particles through non-enzymatic mechanisms. Progression lines represent the mean of two measurements.

Table 3 Molecular mass and polydispersity of labeled and unlabeled material from ex vivo IPP incorporation.

\begin{tabular}{|c|c|c|c|}
\hline rubber sample & $\overline{\mathrm{M}}$ w $\left(10^{5} \mathrm{Da}\right)$ & $\bar{M} n\left(10^{5} \mathrm{Da}\right)$ & $\bar{M} w \bar{M}^{-1}$ \\
\hline unlabeled $\overline{\mathbf{X}}$ 5-120 min & $51.7( \pm 1.34)$ & $24.6( \pm 1.42)$ & 2.1 \\
\hline labeled $\overline{\mathbf{X}}_{5-20} \mathrm{~min}$ & $26.5( \pm 1.01)$ & $7.1( \pm 0.45)$ & 3.7 \\
\hline labeled $\overline{\mathbf{X}} 40-120 \mathrm{~min}$ & $22.5( \pm 2.27)$ & $4.1( \pm 0.30)$ & 5.5 \\
\hline
\end{tabular}

In an ex vivo rubber biosynthesis experiment $6.5 \mathrm{mg}$ of freshly prepared rubber particles was incubated with $\left[1-{ }^{14} \mathrm{C}\right] \mathrm{IPP}$ for the time periods indicated. Extracted rubber material for each assay was fractionated by size exclusion chromatography and radioactivity levels were determined by scintillation.

rate was observed for molecules with $\overline{\mathrm{M}} \mathrm{w}$ of 2,000 $2,500 \mathrm{kDa}$. Interestingly, the $\overline{\mathrm{M}} \mathrm{w}$ and $\overline{\mathrm{M}} \mathrm{n}$ of the $\left[1-{ }^{14} \mathrm{C}\right] \mathrm{IPP}$ labeled rubber decreased during the assay (Figure $4 \mathrm{~b}$ ), increasing the polydispersity (Table 3 ) and indicating both the preferential transfer of $\left[1-{ }^{14} \mathrm{C}\right] \mathrm{IPP}$ to long-chain molecules and the possibility that new rubber molecules are synthesized after the depletion of the long-chain starter molecules. The lower molecular mass distribution of labeled molecules in comparison to the starting material suggested that chain termination by transferase complex might occur preferentially in molecules $>2,500 \mathrm{kDa}$. These data indicate that in vivo rubber biosynthesis can be only partially reconstituted in vitro as also suggested by Tangpakdee et al. [37].

\section{Particle associated cis-1,4-polyprenylcistransferases}

Recently, we identified and isolated three T. koksaghyz CPTs designated TkCPT1-3 [38]. The TkCPT1 and $T k C P T 2$ cDNAs are each $927 \mathrm{bp}$ in length and the TkCPT3 cDNA is $903 \mathrm{bp}$ in length, giving proteins with molecular masses of 32-34 kDa. All three genes are strongly expressed in the latex, but only minimally expressed in other tissues such as leaves, pedicels and roots. Antibodies recognizing the three TkCPTs revealed a strong signal in western blots of the rubber particle fraction of T. koksaghyz latex, with an apparent molecular mass of $34 \mathrm{kDa}$ (Figure 5). Although it has previously been suggested that rubber transferases are associated with rubber particles [39-41], our results for TkCPTs are the first to confirm this theory explicitly.

\section{Functional analysis of TKCPT1-3}

To determine whether the three isolated CPT genes encode functional proteins with long chain cis-prenyltransferase activity in vivo, the cDNAs were expressed in the yeast strain SNH23-7D (Figure 6a), which is a temperature sensitive mutant for the dehydrodolichyl diphosphate (dedol-PP) synthase rer2 [16]. All three $T$. koksaghyz CPTs were able to suppress the growth deficiency phenotype of the rer 2 mutant (Figure 7a), and 


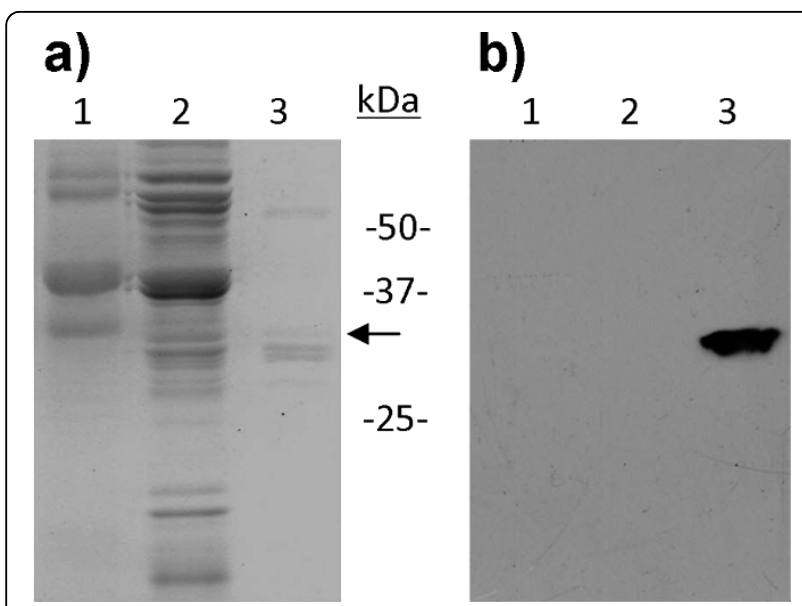

Figure 5 Detection of $T$. koksaghyz CPT in the rubber phase Latex was harvested and divided into pellet (lane 1), C-serum (lane 2) and rubber phase (lane 3). Proteins were separated by SDS-PAGE and either stained with Coomassie Brilliant Blue a) or transferred to a membrane for western blot analysis using antibodies against TkCPTs b).

western blot analysis of the complementing yeast transformants revealed the expression of full length TkCPT13 proteins (Figure $7 \mathrm{~b}$ ). The suppression of the temperature sensitive phenotype demonstrated clearly that TkCPT1-3 catalyze the synthesis of the cis-polyprenol dedol-PP, which has a molecular mass of 1.1-1.3 kDa. Similar results were obtained for HRT2, which is believed to be the long-chain rubber producing CPT in $H$. brasiliensis [25]. The formation of high-molecularmass polyprenols in yeast is possibly repressed by the rapid de-phosphorylation of the dedol-PP to dolichol, which is not a substrate for the chain elongation process. It has previously been suggested that rubber transferases need co-factors for stability and activity [25,29] but our experiments indicate that, at least for $T$.

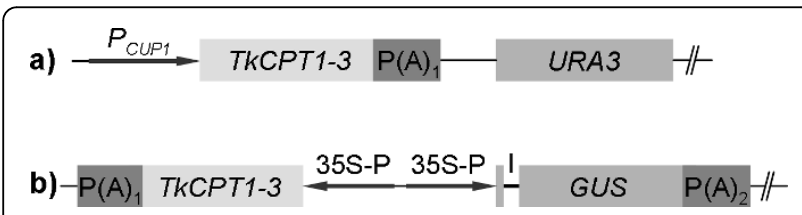

Figure 6 Plasmids for heterologous expression of TkCPT1-3. For heterologous expression of TKCPT1-3 in S. cerevisiae and protoplasts of $N$. tabacum the corresponding cDNAs were cloned into the plasmids pYEX-BX a) and pCAMBIA-1305.1 b), respectively. PCUP1, S. cerevisiae CUP1 promoter; $P(A)_{1}$, cauliflower mosaic virus (CaMV) 355 polyadenylation signal sequence; URA3, S. cerevisiae URA3 locus; 35SP, CaMV 35 S promoter; GUS, beta-glucuronidase synthetic construct including catalase intron (I) (GenBank: AAK29426); $P(A)_{2}$, Agrobacterium tumefaciens D-nopaline synthase polyadenylation signal sequence. koksaghyz CPTs under our experimental conditions, this does not appear to be the case.

More detailed analysis of TkCPT activity was carried out using $N$. tabacum mesophyll protoplasts transfected with each of the cDNAs (Figure 6b, Table 4). In order to avoid qualitative or quantitative differences in protoplast and/or plasmid DNA preparations interfering with the direct comparison of CPT activities between transfection experiments, beta-glucuronidase was coexpressed from the same plasmid as an internal standard as described by Lepetit et al. [42]. Protein extracts from protoplasts expressing each of the TkCPTs showed strong IPP transferase activity, with no significant difference between the three cDNAs. It is therefore most likely that all three enzymes act cooperatively in $T$. koksaghyz rubber biosynthesis.

\section{Conclusion}

We have investigated the physical properties and developmental profile of rubber particles from T. koksaghyz latex and have shown that they possess intrinsic cis-1,4polyprenylcistransferase (rubber transferase) activity of $0.2 \mathrm{pmol} \mathrm{min}^{-1} \mathrm{mg}^{-1}$ which can be partially reconstituted in vitro without further co-factors. We are the first to demonstrate conclusively that CPTs are an intrinsic part of the rubber particle and we have demonstrated a correspondence between the CPT activity in isolated rubber particles and the recently identified CPT genes TkCPT13 in T. koksaghyz, which are able to complement a yeast strain deficient in CPT activity and maintain their activity in tobacco protoplasts. In vitro rubber biosynthesis experiments resulted in a skewed unimodal distribution of $\left[1-{ }^{14} \mathrm{C}\right]$ isopentenyl pyrophosphate (IPP) incorporation at a weight average molecular mass of 2,500 kDa. Our data indicate that TkCPT1-3 are responsible for the rubber chain elongation that occurs in T. koksaghyz rubber particles and that their roles in this regard may be redundant. Our experiments provide crucial background information that will allow the development of T. koksaghyz as a potential alternative commercial source of rubber.

\section{Methods}

\section{Plant material and cultivation conditions}

Taraxacum koksaghyz plants were obtained from the Botanical Gardens Karlsruhe (Karlsruhe, Germany) and cultivated at $18^{\circ} \mathrm{C}$ with a 16 -h photoperiod (20 klx) in controlled growth chambers or in the greenhouse. Plants were cultivated in a prefertilized 1:1 mixture of standard soil (ED73 Einheitserde, Fröndenberg, Germany) and garden mold (Botanical Garden Münster, Germany) and fertilized every 4 weeks with a commercial fertilizer according to the manufacturer's recommendations (Hakaphos Plus, Compo GmbH, Münster, Germany). 


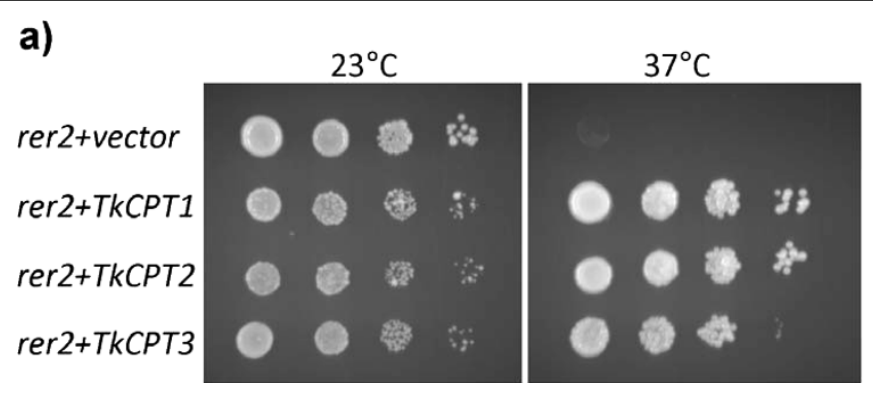

b)

strain SNH23-D7 transformed with plasmid pYEX-BX, pYEX-TKCPT1, pYEX-TKCPT2 and pYEX-TKCPT3 were dropped on SD-URA plates and incubated for 2 days at the temperatures shown. b) Western blots were performed with antibodies against TkCPTs to detect TkCPT in yeast SNH23-D7 (rer2) transformants pYEX-BX (vector control) (1), pYEX-TKCPT1 (2), pYEX-TkCPT2 (3) and pYEX-TkCPT3 (4).

Table 4 Heterologous expression of TkCPTs in Nicotiana tabacum protoplasts.

\begin{tabular}{cccc}
\hline Enzymes & $\begin{array}{c}\text { GUS activity } \\
\left(\boldsymbol{\mu} \text { mol } \mathbf{~ m i n}^{-1} \boldsymbol{\mu \mathbf { g } ^ { - 1 } )}\right.\end{array}$ & $\begin{array}{c}\text { CPT activity } \\
\left(\mathbf{p m o l ~} \mathbf{~ m i n}^{-\mathbf{1}} \mathbf{~ m g}^{-\mathbf{1}}\right)\end{array}$ & CPT/GUS ratio \\
\hline GUS/- & $1.78( \pm 0.10)$ & - & - \\
GUS/TKCPT1 & $1.34( \pm 0.16)$ & $3.48( \pm 0.38)$ & $2.73( \pm 0.50)$ \\
GUS/TKCPT2 & $0.97( \pm 0.15)$ & $2.05( \pm 0.37)$ & $2.28( \pm 0.70)$ \\
GUS/TKCPT3 & $1.22( \pm 0.21)$ & $2.90( \pm 0.64)$ & $2.50( \pm 0.16)$ \\
\hline
\end{tabular}

Protoplasts were transfected with plasmids containing both GUS and TKCPTS or GUS alone in all cases controlled by the CaMV 355 promoter. Protoplast protein extracts were used for measurement of enzyme activities, whereas GUS activity served as the internal standard for normalization of transfection experiments. Values represent mean ( \pm standard deviation) from six biological repetitions. No significant differences existed in enzyme activity between TKCPT1, TkCPT2 and TkCPT3, as calculated using Student's t-test $(P, 0.01)$.

\section{Rubber preparation and determination}

For the isolation of native and functional rubber particles we followed the general procedure described for $\mathrm{H}$. brasiliensis $[27,43]$ with the following modifications. Latex was harvested from petioles or roots of 20 week old T. koksaghyz plants, if not stated otherwise, by dissecting the tissue with a razor blade and transferring the expelling latex into an equal volume of ice-cold rubber extraction buffer (100 mM Tris.Cl (pH 7.8), $350 \mathrm{mM}$ sorbitol, $10 \mathrm{mM}$ $\mathrm{NaCl}, 5 \mathrm{mM} \mathrm{MgCl}_{2}, 5 \mathrm{mM}$ DTT) and centrifuging $\left(12,000 \times g, 20 \mathrm{~min}, 4^{\circ} \mathrm{C}\right)$. The latex separated into three fractions (pellet, $\mathrm{C}$-serum and rubber phase) the latter two of which were transferred to a new tube and centrifuged as above. The rubber phase containing the rubber particles was transferred to a fresh tube and washed with $800 \mu \mathrm{l}$ rubber extraction buffer and then dissolved in rubber extraction buffer and stored briefly at $4^{\circ} \mathrm{C}$. To determine the dry rubber content, $20 \mu \mathrm{l}$ of latex was transferred to a fresh tube and gently overlaid with $20 \mu \mathrm{l}$ glacial acetic acid to coagulate the rubber particles. Afterwards, the coagulum was air-dried for $24 \mathrm{~h}$.

\section{Photon correlation spectroscopy}

Freshly prepared rubber particles were dispersed by brief ultrasonication and then filtered with a $5 \mu \mathrm{m}$ syringe filter prior to dynamic light scattering with a Zetasizer Nano ZS (Malvern Instruments GmbH, Herrenberg, Germany) containing a He-Ne laser $(4.0 \mathrm{~mW}$ at 633 $\mathrm{nm})$ and an Avalanche photodiode detector with a Q.E. $>50 \%$ at $633 \mathrm{~nm}$. Measurements were performed according to the manufacturer's instructions.

\section{Transmission electron microscopy}

Freshly prepared T. koksaghyz latex rubber phase was diluted 1:3 with rubber extraction buffer containing 1 mM DTT, and a small droplet was placed for $1 \mathrm{~min}$ on a freshly glow-discharged carbon layer (thickness $\sim 10$ $\mathrm{nm}$ ) onto a Pioloform film supported by a commercial $\mathrm{Cu}$-mesh grid. After removing excess liquid, the grid was washed with double-distilled water and stained with $2 \%$ aqueous uranyl acetate for $30 \mathrm{~s}$ before air drying. Transmission electron microscopy (TEM) was carried out using a Philips EM 410 (acceleration voltage $80 \mathrm{kV}$ ) in the bright-field mode, and micrographs were recorded on Imaging Plates (Ditabis, Pforzheim, Germany).

\section{IPP-incorporation assay}

To measure the incorporation of IPP into rubber, the latex rubber phase was mixed with assay buffer to a final concentration of $100 \mathrm{mM}$ Tris- $\mathrm{HCl}(\mathrm{pH} 7.5), 2.5 \mathrm{mM}$ $\mathrm{CaCl}_{2}, 10 \mathrm{mM}$ DTT, $1 \mathrm{mM}$ sodium azide, 0.05\% Triton $\mathrm{X}-100,5 \mathrm{mM} \mathrm{MgCl} 2,2.8 \mu \mathrm{M}$ E,E- farnesyl diphosphate (Sigma-Aldrich) and 7.2 $\mu \mathrm{M}\left[1-{ }^{14} \mathrm{C}\right]-$ or $\left[1,2,4-{ }^{13} \mathrm{C}_{3}\right]$ isopentenyl pyrophosphate (IPP) (GE Healthcare). The reaction mixture was incubated at $30^{\circ} \mathrm{C}$ for $2 \mathrm{~h}$ and then stopped by heating to $95^{\circ} \mathrm{C}$ for $5 \mathrm{~min}$. The reaction products were hydrolyzed to corresponding alcohols using

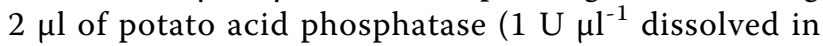
double-distilled water) and $398 \mu \mathrm{l}$ phosphatase buffer (50 $\mathrm{mM}$ sodium acetate $(\mathrm{pH} 4.7), 0.1 \%$ Triton $\mathrm{X}-100,60 \%(\mathrm{v} /$ v) methanol) for $2 \mathrm{~h}$ at $37^{\circ} \mathrm{C}$ as described [44]. The products were extracted by shaking with $600 \mu \mathrm{l}$-hexane for $1 \mathrm{~h}$, air dried and resuspended in $300 \mu \mathrm{l}$-hexane. 
Radioactivity was measured using a scintillation counter (Beckman Scintillation Counter LS6500) after mixing 50 $\mu \mathrm{l}$ of the extracts with $4 \mathrm{ml}$ Rotiszint ${ }^{\oplus}$ eco plus (Roth, Karlsruhe, Germany). Extracts were air dried and resolved in tetrahydrofuran. Size-exclusion chromatography to determine the molecular size distribution of natural rubber and rubber produced in radioactive assays was carried out as previously described [45].

\section{NMR spectroscopy}

One-dimensional ${ }^{1} \mathrm{H}$ and ${ }^{13} \mathrm{C}$ NMR spectra were measured at 500 and $125 \mathrm{MHz}$, respectively, using a DRX500 or AVANCE 500 spectrometer (Bruker, Rheinstetten, Germany). Two-dimensional HMQC, HMBC and COSY spectra were measured with the AVANCE 500 spectrometer using an inverse probe-head and standard parameter sets implemented in TOPSPIN 1.1. The solvent was deuterated dichloromethane and the temperature was $27^{\circ} \mathrm{C}$. The experimental time for ${ }^{13} \mathrm{C}$ NMR spectra was typically $15 \mathrm{~h}$ (corresponding to more than 10,000 scans). Data were processed using TOPSPIN 1.1 or MestReNova.

\section{Construction of expression vectors for heterologous expression}

RNA from T. koksaghyz latex was isolated as described previously [45] and cDNA synthesis was carried out using the SuperScript II $^{\mathrm{TM}}$ Reverse Transcriptase Kit (Invitrogen, Karlsruhe, Germany) with an oligo(dT) primer. For all three TkCPTs (TkCPT1, TkCPT2 and $T k C P T 3)$ cDNA was generated using the primer combination cpt-TK_EcoRI (5'-AAA GAA TTC ATG CAA GTG AAT CCA ATC ATT ACT AC-3') and cpt-TKrev_SalI (5'-AAA GTC GAC TTA TGC CTG CTT CTT CTT CTT CTC C-3'). The products were inserted into the $\mathrm{pCRII-TOPO}^{\circ}$ vector (Invitrogen, Karlsruhe, Germany), sequenced and then transferred using EcoRI and SalI restriction sites into the expression vector pGEX4T1 (GE Healthcare Europe GmbH, Freiburg, Germany). This allowed the expression of TkCPTs as N-terminal fusions to glutathione-S-transferase (GST) for heterologous expression in Escherichia coli BL21-cells and downstream antibody generation.

For heterologous expression of TkCPT1-3 in Nicotiana tabacum var. SR1 protoplasts, the corresponding cDNAs were amplified with the primers TkCPT_Pcil (5'-AAA ACA TGT TAC AAG TGA ATC CAA TCA TTA CTA C-3') and TkCPT-rev_XbaI (5'-AAA ACA TGT TAC AAG TGA ATC CAA TCA TTA CTA C-3') and transferred using the NcoI and $\mathrm{XbaI}$ sites into the pUC18based pAM vector containing the CaMV $35 \mathrm{~S}$ promoter and polyadenylation sequences from pRT104 [46]. The cassette was then transferred using the $K p n I$ and EcoRI sites into pCAMBIA-1305.1 (GenBank: AF354045), which already contains the gusA reporter gene including a catalase intron under the control of the CaMV $35 \mathrm{~S}$ promoter.

For expression in yeast, the $T k C P T$ cDNAs were released from pAM using XhoI and EcoRI and introduced into vector pYEXBX (Clontech Laboratories Inc., Saint-Germain-en-Laye, France), which had been digested with SalI and EcoRI.

\section{Generation of antibodies against TkCPTs}

The three TkCPT clones in pGEX4-T1 were overexpressed in 300-ml cultures of E. coli strain BL21, induced with $1 \mathrm{mM}$ isopropyl-beta-D-thiogalactopyranoside (IPTG). Purified TkCPT1 was sequenced by MALDI-MS and administered to rabbits by EUROGENTEC (Seraing, Belgium). The pre-immune and antibody sera were tested for specificity by western blot against the recombinant proteins TkCPT1, TkCPT2 and TKCРT3.

\section{SDS-PAGE and western blots}

SDS-PAGE was carried out using $15 \mu \mathrm{g}$ protein per lane from the pellet, $\mathrm{C}$-serum and rubber phases of fresh $T$. koksaghyz latex. Protein concentrations were determined using the Bradford method [47]. Proteins were separated on SDS-PAGE gels and either stained with Coomassie Brilliant Blue or transferred to nitrocellulose membranes as described [48]. The membranes were incubated with the primary antibody (1:500 dilution) for $1 \mathrm{~h}$ at room temperature, washed and then incubated with a mouse anti-rabbit IgG conjugated to horseradish peroxidase (Sigma, Munich, Germany) according to the manufacturer's instructions. Membranes with HRP-coupled secondary antibodies were imaged on X-ray films by chemiluminescence detection.

\section{Expression of TkCPTs in yeast}

Yeast strain SNH23-D7 (MATa rer2-2 mfa1::ADE2 mfa2::TRP1 bar1::HIS3 ade2 trp1 his3 leu2 ura3 lys2) [16] was cultivated in standard YPD medium for $48 \mathrm{~h}$ at $20^{\circ} \mathrm{C}$, then transformed [49] with pYEXBX-TkCPT1-3, and the pYEXBX base vector as a control. After regeneration, cells were plated on SD-URA agar, colonies for each construct were transferred to $0.9 \% \mathrm{NaCl}$ and adjusted to different optical densities (1, 0.1, 0.01 and 0.001 ) and 5- $\mu \mathrm{l}$ droplets were spotted onto SD-URA plates. After $48 \mathrm{~h}$ incubation in SD-URA liquid medium, denatured protein extracts were prepared from 20 $\mathrm{OD}_{600}$ units [50] and used for SDS-PAGE and western blot analysis.

\section{Expression in protoplasts and GUS assay}

Protoplasts were isolated from Nicotiana tabacum var. $\mathrm{SR} 1$ and $\mathrm{Ca}\left(\mathrm{NO}_{3}\right)_{2}$ polyethylene glycol-mediated DNA 
transfer was performed as described [51] using $3.3 \times 10^{5}$ protoplasts and $10 \mu \mathrm{g}$ of pCambia1305.1-TkCPT1-3 DNA per transfection. Frozen protoplasts were sheared in IPP assay buffer, briefly centrifuged and the supernatants pooled from six replicate transfections. Protein concentration was determined using the Bradford method [47] and bovine serum albumin as a standard. Approximately $100 \mu \mathrm{g}$ of protein extract was used in the IPP incorporation assay and $1 \mu \mathrm{g}$ in the glucuronidase activity assay with 4-methylumbelliferylglucuronide (4MUG) as the substrate [52].

\section{Funding}

This work was supported by a grant from the Ministry of Science and Education of Germany (grant no. FKZ 0313712), by EVONIK Industries AG, by the HansFischer Gesellschaft Munich (to WE), by the Deutsche Bundesstiftung Umwelt (to ML) and the federal state North-Rhine Westphalia co-financed by the European Union.

\begin{abstract}
Abbreviations
4-MUG: 4-methylumbelliferylglucuronide; ACPT: Arabidopsis thaliana cisprenyltransferase; COSY: correlation spectroscopy; CPT: cis-1,4polyprenylcistransferases; FPP: farnesyl pyrophosphate; GUS: betaglucuronidase; HMBC: heteronuclear multiple bond correlation; HMQC: heteronuclear multiple quantum coherence; HRT: Hevea brasiliensis rubber transferase; IPP: isopentenyl pyrophosphate; NMR: nuclear magnetic resonance; RER2: Saccharomyces cerevisiae dehydrodolichyl diphosphate synthase; SEC: size exclusion chromatography; SRT1: Saccharomyces cerevisiae cis-1,4-polyprenylcistransferases; TEM: transmission electron microscopy; TkCPT: Taraxacum koksaghyz cis-1,4-polyprenylcistransferases; TPT: transprenyltransferase
\end{abstract}

\begin{abstract}
Acknowledgements
The authors would like to thank Ursula Malkus (Institut für Medizinische Physik und Biophysik, Münster) for carrying out the TEM analysis of rubber particles. The technical assistance of Sandra Ponanta (Institut für Biochemie und Biotechnologie der Pflanzen, Münster), Raphael Soeur (Fraunhofer Institut für Molekularbiologie und Angewandte Ökologie, Aachen) and Karin Wacker (Fraunhofer Institut für Chemische Technologie, Pfinztal) is gratefully acknowledged. We would like to thank Prof. Dr. Thomas Hirth (Fraunhofer Institut für Grenzflächen und Bioverfahrenstechnik, Stuttgart) and Dr. Ulrich Fehrenbacher (Fraunhofer Institut für Chemische Technologie, Pfinztal) for providing SEC and PCS facilities. We are grateful to Dr Akihiko Nakano and Dr Ken Sato (RIKEN, Japan) for kindly providing the yeast strain SNH23-D7.
\end{abstract}

\section{Author details}

${ }^{1}$ Institut für Biochemie und Biotechnologie der Pflanzen, Westfälische Wilhelms-Universität Münster, Hindenburgplatz 55, 48143 Münster, Germany. ${ }^{2}$ Institut für Medizinische Physik und Biophysik, Westfälische WilhelmsUniversität Münster, Robert-Koch Str. 31, D-48149 Münster, Germany. ${ }^{3}$ Department Chemie, Lehrstuhl für Biochemie, Technische Universität München, Lichtenbergstrasse 4, 85748 Garching, Germany. ${ }^{4}$ Fraunhofer Institut für Molekularbiologie und Angewandte Ökologie, Forckenbeckstr. 6, 52074 Aachen, Germany.

\section{Authors' contributions}

TS contributed to results presented in figures 1, 3 and 4. ML generated antibodies and performed experiments for figures 5 and 7. AH, NvD and OM performed heterologous expression of TKCPT in tobacco protoplasts (Table 3) and yeast (Figure 7). RR did the transmission electron microscopy (Figure 1) and WE the nuclear magnetic resonance spectroscopy (Figures 2 and 3c). RF helped with the interpretation of data. DP and CSG set up the experimental outline and prepared the manuscript. All authors read and approved the final manuscript.

Received: 15 October 2009

Accepted: 19 February 2010 Published: 19 February 2010

\section{References}

1. van Beilen $J B$, Poirier $Y$ : Establishment of new crops for the production of natural rubber. Trends Biotechnol 2007, 25:522-529.

2. Ray DT: Guayule: A source of natural rubber. New Crops Wiley New York, New YorkJanick J, Simon JE 1993, 338-343.

3. Yagami A, Suzuki K, Saito H, Matsunaga K: Hev b 6.02 is the most important allergen in health care workers sensitized occupationally by natural rubber latex gloves. Allergol Int 2009, 58:347-355.

4. Gomez JB, Hamzah S: Particle size distribution in Hevea latex - some observations on the electron microscopic method. J Nat Rubber Res 1989, 4:204-211.

5. Yeang HY, Yip E, Hamzah S: Characterization of zone 1 and zone 2 rubber particles in Hevea brasiliensis latex. J Nat Rubber Res 1995, 10:108-123.

6. Wood DF, Cornish K: Microstructure of purified rubber particles. Int J Plant Sci 2000, 161:435-445.

7. Hasma H, Subramaniam A: Composition of lipids in latex of Hevea brasiliensis clone RRIM 501. J Nat Rubber Res 1986, 1:30-40.

8. Hasma H: Lipids associated with rubber particles and their possible role in mechanical stability of latex concentrates. J Nat Rubber Res 1991, 6:105-114.

9. Siler DJ, Goodrich-Tanrikulu M, Cornish K, Stafford AE, McKeon TA: Composition of rubber particles of Hevea brasiliensis, Parthenium argentatum, Ficus elastica, and Euphorbia lactiflua indicates unconventional surface structure. Plant Physiol Biochem 1997, 35:881-889.

10. Cornish K, Wood DF, Windle JJ: Rubber particles from four different species, examined by transmission electron microscopy and electronparamagnetic- resonance spin labeling, are found to consist of a homogeneous rubber core enclosed by a contiguous, monolayer biomembrane. Planta 1999, 210:85-96.

11. Cornish K, Siler DJ, Grosjean OK, Godman N: Fundamental similarities in rubber particle architecture and function in three evolutionarily divergent plant species. J Nat Rubber Res 1993, 8:275-285.

12. Poulter $C D$, Rilling HC: Prenyltransferase - mechanism of reaction. Biochemistry 1976, 15:1079-1083.

13. Poulter CD, Rilling HC: The prenyl transfer-reaction. Enzymatic and mechanistic studies of $1^{\prime}-4$ coupling reaction in the terpene biosynthetic-pathway. Acc Chem Res 1978, 11:307-313.

14. Kharel $Y$, Koyama T: Molecular analysis of cis-prenyl chain elongating enzymes. Nat Prod Rep 2003, 20:111-118.

15. Kharel Y, Zhang Y, Fujihashi M, Miki K, Koyama T: Identification of significant residues for homoallylic substrate binding of Micrococcus luteus B-P 26 undecaprenyl diphosphate synthase. J Biol Chem 2001, 276:28459-28464.

16. Sato M, Sato K, Nishikawa S, Hirata A, Kato J, Nakano A: The yeast RER2 gene, identified by endoplasmic reticulum protein localization mutations, encodes cis-prenyltransferase, a key enzyme in dolichol synthesis. Mol Cell Biol 1999, 19:471-483.

17. Jones J, Viswanathan K, Krag SS, Betenbaugh MJ: Polyprenyl lipid synthesis in mammalian cells expressing human cis-prenyltransferase. Biochem Biophys Res Commun 2005, 331:379-383.

18. Light DR, Dennis MS: Purification of a prenyltransferase that elongates cis-polyisoprene rubber from the latex of Hevea brasiliensis. J Biol Chem 1989, 264:18589-18597.

19. Siler DJ, Cornish K: A protein from Ficus elastica rubber particles is related to proteins from Hevea brasiliensis and Parthenium argentatum. Phytochemistry 1993, 32:1097-1102.

20. Cornish K, Siler DJ, Grosjean O: Immunoinhibition of rubber particlebound cis-prenyltransferases in Ficus elastica and Parthenium argentatum. Phytochemistry 1994, 35:1425.

21. Cornish K, Siler DJ: Characterization of cis-prenyltransferase activity localized in a buoyant fraction of rubber particles from Ficus elastica latex. Plant Physiol Biochem 1996, 34:334-377.

22. Kang H, Soo Kim Y, Chung GC: Characterization of natural rubber biosynthesis in Ficus benghalensis. Plant Physiol Biochem 2000, 38:979-987. 
23. Sato M, Fujisaki S, Sato K, Nishimura Y, Nakano A: Yeast Saccharomyces cerevisiae has two cis-prenyltransferases with different properties and localizations. Implication for their distinct physiological roles in dolichol synthesis. Genes Cells 2001, 6:495-506.

24. Oh SK, Han K, Ryu SB, Kang H: Molecular cloning, expression, and functional analysis of a cis-prenyltransferase from Arabidopsis thaliana. J Biol Chem 2000, 275:18482-18488.

25. Asawatreratanakul K, Zhang Y, Wititsuwannakul D, Wititsuwannakul R, Takahashi S, Rattanapittayaporn A, Koyama T: Molecular cloning, expression and characterization of CD3A encoding cis-prenyltransferases from Hevea brasiliensis. Eur J Biochem 2003, 270:4671-4680.

26. Berndt J: The biosynthesis of rubber. US Government Res Rep AD-601 1963, 729.

27. Cornish K, Backhaus RA: Rubber transferase activity in rubber particles of guayule. Phytochemistry 1990, 29:3809-3813.

28. Cornish K, Siler DJ: Effect of different allylic diphosphates on the initiation of new rubber molecules and on cis-1,4-polyisoprene biosynthesis in guayule (Parthenium argentatum Gray). J Plant Physiol 1995, 147:301-305

29. Singh AP, Wi SG, Chung GC, Kim YS, Kang H: The micromorphology and protein characterization of rubber particles in Ficus carica, Ficus benghalensis and Hevea brasiliensis. J Exp Bot 2003, 54:985-992.

30. Matzelle T, Reichelt R: Review: Hydro, micro- and nanogels studied by complementary measurements based on SEM and SFM. Acta Microscopica 2008, 17:45-61.

31. Suomela H: On the possibilities of growing Taraxacum kok-saghyz in Finland. National Agricultural Experimental Publications (valtion maatalous koetoiminnan julkaisuja), Helsinki 1950.

32. Duch MW, Grant DM: Carbon-13 chemical shift studies of the 1,4polybutadienes and the 1,4-polyisoprenes. Macromolecules 1970, 3:165-174.

33. Kang $H$, Kang MY, Han K: Identification of natural rubber and characterization of rubber biosynthetic activity in fig tree. Plant Physiol 2000, 123:1133-1142.

34. Cornish $\mathrm{K}$ : Similarities and differences in rubber biochemistry among plant species. Phytochemistry 2001, 57:1123-1134.

35. da Costa BMT: Regulation of rubber biosynthetic rate and molecular weight in Hevea brasiliensis by metal cofactor. Biomacromolecules 2005, 6:279.

36. Scott DJ, da Costa BMT, Espy SC, Keasling JD, Cornish K: Activation and inhibition of rubber transferases by metal cofactors and pyrophosphate substrates. Phytochemistry 2003, 64:123-134.

37. Tangpakdee J, Tanaka Y, Ogura K, Koyama T, Wititsuwannakul R, Wititsuwannakul D: Rubber formation by fresh bottom fraction of Hevea latex. Phytochemistry 1997, 45:269-274.

38. Schmidt T, Hillebrand A, Wurbs D, Wahler D, Lenders M, Schulze Gronover C, Prüfer D: Molecular cloning and characterization of rubber biosynthetic genes from Taraxacum koksaghyz . Plant Mol Biol Rep, doi. org/10.1007/s11105-009-0145-9.

39. Archer BL, Audley BG, Cockbain EG, McSweeny GP: The biosynthesis of rubber - incorporation of mevalonate and isopentenyl pyrophosphate into rubber by Hevea brasiliensis -latex fractions. Biochem J 1963, 89:565-574.

40. McMullen Al, McSweeny GP: The biosynthesis of rubber: Incorporation of isopentenyl pyrophosphate into purified rubber particles by a soluble latex serum enzyme. Biochem J 1966, 101:42.

41. Lynen F: Biosynthetic pathways from acetate to natural products. Pure Appl Chem 1967, 14:137-167.

42. Lepetit $M$, Ehling M, Gigot C, Hahne G: An internal standard improves the reliability of transient expression studies in plant protoplasts. Plant Cell Rep 1991, 10:401-405.

43. Wititsuwannakul D, Rattanapittayaporn A, Koyama T, Wititsuwannakul R: Involvement of Hevea latex organelle membrane proteins in the rubber biosynthesis activity and regulatory function. Macromol Biosci 2004, 4:314-323.

44. Fujii H, Koyama T, Ogura K: Efficient enzymatic hydrolysis of polyprenyl pyrophosphates. Biochim Biophys Acta - Lipids and Lipid Metabolism 1982, 712:716-718

45. Wahler D, Schulze Gronover C, Richter C, Foucu F, Twyman RM, Moerschbacher BM, Fischer R, Muth J, Prüfer D: Polyphenoloxidase silencing affects latex coagulation in Taraxacum spp. Plant Physiol 2009, 151:334-346.
46. Toepfer R, Matzeit V, Gronenborn B, Schell J, Steinbiss H: A set of plant expression vectors for transcriptional and translational fusions. Nucl Acids Res 1987, 15:5890.

47. Bradford MM: A rapid and sensitive method for the quantitation of microgram quantities of protein utilizing the principle of protein-dye binding. Anal Biochem 1976, 72:248-254.

48. Towbin H, Staehelin T, Gordon J: Electrophoretic transfer of proteins from polyacrylamide gels to nitrocellulose sheets: Procedure and some applications. Proc Natl Acad Sci USA 1979, 76:4350-4354.

49. Gietz D, Jean AS, Woods RA, Schiestl RH: Improved method for high efficiency transformation of intact yeast cells. Nucl Acids Res 1992, 20:1425.

50. Baerends RJS, Faber KN, Kram AM, Kiel JAKW, Klei van der IJ, Veenhuis M: A stretch of positively charged amino acids at the 3 terminus of Hansenula polymorpha Pex3p is involved in incorporation of the protein into the peroxisomal membrane. J Biol Chem 2000, 275:9986-9995.

51. Negrutiu I, Shillito R, Potrykus I, Biasini G, Sala F: Hybrid genes in the analysis of transformation conditions. Plant Mol Biol 1987, 8:363-373.

52. Jefferson RA, Kavanagh TA, Bevan MW: GUS fusions - beta-glucuronidase as a sensitive and versatile gene fusion marker in higher-plants. EMBO J 1987, 6:3901-3907.

doi:10.1186/1471-2091-11-11

Cite this article as: Schmidt et al:: Characterization of rubber particles and rubber chain elongation in Taraxacum koksaghyz. BMC Biochemistry 2010 11:11.

\section{Submit your next manuscript to BioMed Central and take full advantage of:}

- Convenient online submission

- Thorough peer review

- No space constraints or color figure charges

- Immediate publication on acceptance

- Inclusion in PubMed, CAS, Scopus and Google Scholar

- Research which is freely available for redistribution

Submit your manuscript at www.biomedcentral.com/submit
C Biomed Central 